\title{
Jogos materno-infantis: estimulação essencial para a criança com paralisia cerebral
}

\author{
Mother-infant play: essential stimulation \\ for children with cerebral palsy
}

\author{
Celina Aguilar GOMES \\ Edison DUARTE²
}

\begin{abstract}
Resumo
O objetivo deste estudo foi verificar a influência potencial de atividades lúdicas, realizadas no contexto hospitalar, sobre os processos desenvolvimentais de crianças com paralisia cerebral, a partir da análise dos elementos do microssistema de Urie Bronfenbrenner. Partindo de uma abordagem qualitativa, esta pesquisa se caracterizou como um estudo de caso interpretativo. Quatro crianças com paralisia cerebral e suas mães foram selecionadas como sujeitos desta pesquisa, realizada na sala de espera da Fisioterapia Neurológica Infantil do Hospital das Clínicas da Universidade Estadual de Campinas. O critério de escolha foi: diagnóstico de paralisia cerebral, assiduidade ao atendimento fisioterápico e concordância em participar de todas as etapas da pesquisa. Os instrumentos de pesquisa foram: observação participante e entrevista semiestruturada. Os resultados revelaram uma mudança positiva nas atitudes das mães e das crianças em relação ao ambiente.
\end{abstract}

Unitermos: Paralisia cerebral. Brincar. Desenvolvimento. Interação infantil.

\begin{abstract}
The aim of this research was to ascertain the potential influence of ludic activities conducted in a hospital environment, on the developmental processes of children with cerebral palsy, based on an analysis of the microsystem elements per Urie Bronfenbrenner. Starting from a qualitative approach, this research was characterized as an interpretative case study. Four children with CP and their mothers participated in this research that took place in the "waiting room" of the pediatric neurological physical therapy unit at the Universidade Estadual de Campinas (University Hospital). The criteria chosen were as follows: the CP diagnosis, therapy attendance and the agreement to participate. The research tools used were: participant observation and semi-structured interviews. The data analysis revealed a positive change in the attitude of the mothers and children in relation to the environment.
\end{abstract}

Uniterms: Cerebral palsy. Recreation. Childhood development. Interpersonal relations.

Há muito se reconhece que a influência psicológica do ambiente sobre o desenvolvimento da criança é de extrema importância. Realmente, todos os aspectos do comportamento (instintivo, voluntário, lúdico, emocional) são codeterminados pelo meio existente (Lewin, 1975). Assim, conceber o desenvolvimento como o produto da interação entre o organismo humano em crescimento e seu ambiente é uma propo-

$\boldsymbol{\nabla} \boldsymbol{\nabla} \boldsymbol{\nabla}$

1 Universidade Estadual de Campinas, Programa de Pós-Graduação Mestrado em Educação Física. Cidade Universitária Zeferino Vaz, Barão Geraldo, 13081 970, Campinas, SP, Brasil. Correspondência para/Correspondence to: C.A. GOMES. E-mail: <celina_aguilar2005@yahoo.com.br>.

2 Universidade Estadual de Campinas, Faculdade de Educação Física, Departamento de Atividade Motora Adaptada. Campinas, SP, Brasil. 
sição que poucos considerariam extraordinária. Urie Bronfenbrenner foi um destes poucos.

Ao publicar, no final da década de 1970, "A ecologia do desenvolvimento humano", Bronfenbrenner (2002) destacou o princípio, expresso simbolicamente na clássica equação de Lewin (1975): $C=f(P A)$, de que o comportamento (C) evolui da interação entre a pessoa (P) e o ambiente (A), dando uma ênfase equivalente a ambos os elementos da equação.

Na perspectiva teórica de Bronfenbrenner (2002), o ambiente ecológico é concebido como uma série de estruturas encaixadas, como "um conjunto de bonecas russas". No nível mais interno está o entorno imediato contendo a pessoa desenvolvente (microssistema). O passo seguinte desta concepção, no entanto, requer um olhar para ambientes além destes espaços "simples", bem como para as relações entre eles. Esta interconexão é decisiva, pois o desenvolvimento da pessoa é intensamente afetado por episódios que ocorrem em locais nos quais o indivíduo nem sequer está presente.

O ponto central desta orientação ecológica está na preocupação com a adaptação progressiva entre o organismo humano em crescimento e seu ambiente imediato, assim como na maneira pela qual essa relação é influenciada por forças procedentes de regiões distantes do meio físico e social (Bronfenbrenner, 2002).

Ao discutir estas questões, o autor reconheceu que seria impossível ignorar o papel crucial desempenhado por características pessoais no desenvolvimento. Do mesmo modo, ponderou que o comportamento de um indivíduo não depende inteiramente da situação presente, envolvendo uma ampliação da perspectiva de tempo.

Tais reflexões resultaram em uma complementação de seus estudos e, cerca de uma década após a publicação de "A ecologia do desenvolvimento humano", Bronfenbrenner (2005) integrou o termo bioecologia ao modelo inicial, oferecendo uma reorientação ecológica constituída por quatro componentes intimamente relacionados. São eles: processo (relação dinâmica entre indivíduo e contexto), pessoa (com seu repertório individual de características biológicas, cognitivas, emocionais e comportamentais), contexto (concebido como "estruturas encaixadas" ou sistemas) e tempo 554 (envolvendo múltiplas dimensões de temporalidade).
A inclusão do fator tempo oferece particular atenção ao que se chama de eventos e experiências, que podem ter sua origem no ambiente externo (como a entrada na escola, o nascimento de um filho deficiente) ou no próprio organismo (a chegada da puberdade ou uma grave doença). Tais fatores alteram a relação existente entre indivíduo e ambiente, criando uma dinâmica capaz de incitar profundas mudanças desenvolvimentais (Bronfenbrenner, 2005).

Com efeito, uma importante característica da criança pequena é ser essencialmente presente. Mas a história tal como ela a experimenta é um constituinte fundamental dos elementos do ambiente. Por outro lado, a extensão do mundo infantil para o futuro procede do fato de que a criança, por meio da experiência, aprende a observar relações cada vez mais extensas e, a partir de certo momento, não só os episódios ocorridos há muitos meses, mas também os que ocorrerão no futuro desempenham um importante papel no comportamento presente:"As metas são continuamente projetadas no futuro. Desse modo, o comportamento do indivíduo não depende inteiramente da situação presente, mas inclui o passado, o presente e o futuro psicológicos, que constituem o"espaço de vida"existente num determinado momento. "À situação psicológica pertencem não somente aqueles fatos que são realmente perceptíveis e objetivamente atuais, mas também toda uma gama de eventos passados e futuros. Uma censura ou um elogio, por exemplo, podem permanecer por muito tempo como um fato psicológico presente para a criança" (Lewin, 1975).

Outro importante aspecto levantado pelo modelo bioecológico de Bronfenbrenner (2005), e anteriormente enfatizado por Lewin (1975), ressalta que a dinâmica das influências ambientais somente pode ser investigada com a determinação das diferenças individuais. Com efeito, indivíduos distintos possuem características próprias de temperamento, personalidade e atributos físicos. Tais peculiaridades devem ser consideradas como constituintes do contexto no qual se manifestam, e não simplesmente "anexos", pelo fato de serem capazes de suscitar reações - positivas ou negativas - no meio circundante. Exemplos incluem um comportamento social agradável versus apatia ou dificuldade de comunicação; boa aparência versus deficiência física. 
Lewin (1965), em seu conceito de "espaço de vida", ou "campo psicológico", pondera que o ambiente de maior relevância para o entendimento científico do comportamento e desenvolvimento não deve ser descrito em termos "fisicamente objetivos", mas conforme ele existe para a pessoa naquele momento.

Em termos de método de pesquisa, no entanto, a "construção da realidade desenvolvente" na criança não pode ser observada diretamente, podendo apenas ser compreendida a partir de padrões de atividades, conforme se apresentam em comportamentos verbais e não verbais durante atividades molares, papéis e relações em que ela se envolve. Estes três fatores constituem os chamados elementos do microssistema (Bronfenbrenner, 2002):

- Atividade molar: comportamento continuado, ou seja, apresenta uma persistência temporal, e é percebido como possuidor de significado ou intenção pelos participantes do ambiente. As atividades molares adquirem, no entanto, maior complexidade ao introduzirem outro elemento do microssistema - as relações com outras pessoas. As crianças, em especial, passam muito tempo em atividades com outros adultos e crianças. No início tais "interações" costumam envolver apenas uma pessoa por vez, mas logo a criança se torna capaz de lidar com duas ou mais pessoas simultaneamente, o que Bronfenbrenner (2002) considera um importante princípio da ecologia do desenvolvimento.

- Relação interpessoal:"sempre que uma pessoa em um ambiente presta atenção às atividades de uma outra pessoa, ou delas participa, existe uma relação" (Bronfenbrenner, 2002, p. 46). A condição mínima para a existência de uma díade, ou sistema de duas pessoas, é a presença de uma relação recíproca. A díade pode ser considerada o "bloco construtor básico" do microssistema, assumindo três formas funcionais descritas por Bronfenbrenner (2002):

1) Díade observacional: "ocorre quando um membro está prestando uma cuidadosa e continuada atenção à atividade do outro, que, por sua vez, reconhece o interesse sendo demonstrado" (Bronfenbrenner, 2002, p. 46).

2) Díade de atividade conjunta: "é aquela em que os dois participantes se percebem juntos fazendo algo" (Bronfenbrenner, 2002, p. 47). Tais atividades podem ser diferentes, porém necessariamente complementares. Ao participarem de uma atividade conjunta, duas pessoas frequentemente desenvolvem sentimentos mais intensos uma em relação à outra. Na medida em que estes são positivos e recíprocos, favorecem a ocorrência de processos desenvolvimentais, determinando a formação do terceiro tipo de díade:

3) Díade primária: envolve mutualidade de sentimentos positivos.

Particularmente no desenvolvimento infantil, Bronfenbrenner (2005) considera fundamental a participação da criança em padrões de atividades progressivamente mais complexos, por um longo período de tempo, com alguém com quem ela tenha desenvolvido uma forte e mútua ligação emocional e que exerça um papel parental. Para ser mais explícito, somente alguém que tenha uma 'ligação irracional' com a criança será capaz de fazer o que for necessário para favorecer seu desenvolvimento. Quanto ao elemento papel, Bronfenbrenner (2002) considera que o próprio conceito envolve uma integração dos elementos atividade e relação interpessoal, uma vez que se pode defini-lo como "a maneira como a pessoa se comporta numa determinada situação e como os outros agem em relação a ela"(Bronfenbrenner, 2002, p. 69).

A partir das considerações contidas na"Ecologia do Desenvolvimento Humano" de Bronfenbrenner pode-se concluir que as condições ambientais determinam cada aspecto do comportamento da criança, sendo os fatores sociais especialmente determinantes. Desde o nascimento, as interações são fundamentais para a sobrevivência e o desenvolvimento infantil como um todo. Cada etapa do crescimento pressupõe uma ampliação dos laços afetivos e sociais.

O nascimento de uma criança com Paralisia Cerebral (PC), no entanto, gera nos pais uma avalanche de sentimentos contraditórios: angústia, culpa, rejeição, vergonha, desespero, tristeza, isolamento. Não obstante, enquanto tal conflito se desenrola, o bebê está à espera, necessitando de atenção e afeto.

Para a maioria dos pais, o diagnóstico de PC é um mistério sobre o qual eles pouco sabem. As explicações tomam a forma do que está errado com a criança, de quais são os problemas, do que ela não pode fazer, criando, nos pais, uma visão limitada, negativa e pessimista de seu filho. 
As múltiplas intervenções que passam a fazer parte da vida do bebê submetem a família a técnicas de estimulação que deslocam o modo espontâneo de cuidados diários da criança para segundo plano. A maior parte de suas relações é vivida como um"processo terapêutico". Toda a infância poderá, deste modo, ser passada em clínicas, hospitais e instituições, isolando a criança com PC de um "mundo maior". Mesmo em casa, a mãe geralmente é transformada no principal "terapeuta" e, o livre brincar, em "exercícios de reabilitação". Desde o início, o ato físico de segurar e manipular o bebê - prelúdio do "diálogo tônico" mencionado por Ajuriaguerra (1980) - pode ser dificultado pelos padrões anormais de postura e movimento característicos da $P C$. Se esta criança não desenvolveu um controle de cabeça e tronco, por exemplo, este não é apenas um problema funcional. Ela não poderá iniciar a comunicação com a cabeça ou com os olhos para indicar seus desejos e necessidades. A mãe pode achar seu filho difícil de alimentar e embalar, sentindo-se, assim, insegura de suas habilidades maternas (Levitt, 2001). No entanto, seu filho terá a necessidade vital de que ela promova, de um modo especial, os estágios de desenvolvimento.

Escrevem Maturana e Verden-Zöller (2004): “O processo inicial mais importante para o desenvolvimento da consciência humana ocorre na musicalidade elementar dos ritmos corporais vibratórios e sonoros da relação materno-infantil, enquanto a mãe amamenta, acaricia, embala, fala e acalanta o recém-nascido".

Buscaglia (1993) observa que não é raro a mãe de uma criança com deficiência declarar que prefere não sair de casa a levar seu filho. É compreensível a relutância da mãe em expor seu filho a reações frequentemente negativas. Quando uma criança é "bonita" e "saudável" tende-se a reagir de forma positiva. Por outro lado, evita-se o contato extensivo com uma criança "sem atrativos físicos". Bronfenbrenner (2005) reforça tal afirmação considerando que características físicas individuais tendem a gerar reações distintas no meio circundante.

A criação de espaços que respondam às necessidades da criança com PC torna-se, assim, fundamental para o pleno desenvolvimento. Porém, "montar cantinhos" com brinquedos não basta. É preciso uma proposta que ofereça oportunidades para a construção de novas formas de convívio, com atividades e pessoas com as quais a criança possa estabelecer relações de reciprocidade e, consequentemente, de mútua aceitação e amizade.

Em geral, as primeiras transições ecológicas (mudanças de ambiente e consequente ampliação do espaço relacional) ocorrem quando a criança começa a frequentar a casa de familiares ou entra na escola. Tais ambientes costumam ser naturalmente acolhedores (Bronfenbrenner, 2002). Porém, no caso específico de crianças com PC, o direito ao ingresso na escola, garantido pela legislação brasileira, nem sempre é respeitado. "Desculpe, não estamos preparados" é o principal argumento de diretores e professores do ensino regular. Da falta de estrutura física adequada, que possibilite a locomoção, ao despreparo de professores e funcionários, os problemas enfrentados são inúmeros.

A Lei de Diretrizes e Bases da Educação Nacional (de 1996), por sua vez, prevê o atendimento especializado em classes ou escolas especiais, quando não for possível oferecê-lo na escola comum. Embora tenha sido revista pelo decreto n 3.956 (convenção da Guatemala), que deixou clara a incoerência do tratamento desigual com base na deficiência, crianças com severo comprometimento motor têm dificuldade de acesso, inclusive, à educação especial.

Portanto, o maior desafio do processo de inclusão é a adequação ambiental (física e social). Recreio e aulas de Educação Física, por exemplo, são ocasiões propícias para incentivar a socialização por meio de brincadeiras. No entanto, sem um ambiente favorável, podem ser o principal momento de exclusão, quando a criança sente que não pertence verdadeiramente ao grupo. As mães se sentem fragilizadas ao verem seus filhos rejeitados e, "instintivamente", querem protegê-los, limitando ainda mais seu espaço relacional.

A partir destas reflexões, nasceu o "Espaço Jardim Oficina", ambiente de atividades situado na sala de espera da Fisioterapia Neurológica Infantil do Hospital das Clínicas da Universidade Estadual de Campinas (HC-UNICAMP).

Dentro de uma concepção de humanização hospitalar, transforma-se o ambiente, oferecendo, por meio de atividades lúdicas, oportunidades de estimulação motora e social. 
Sabe-se, por experiência, que muitas mães relutam em levar seus filhos deficientes a uma brinquedoteca, a uma sala de jogos, ou mesmo a um parque infantil. Os motivos variam desde a descrença nas possibilidades da criança, ou receio de expô-la ao fracasso e aos olhares curiosos e constrangidos, até o cansaço da mãe. Uma criança deficiente necessita de cuidados e atenção frequentes, que podem se tornar desgastantes à medida que a criança cresce em idade e tamanho. Soma-se a isso a frequente falta de sistemas de apoio, ressaltada por Bronfenbrenner (2002), para essas famílias.

Por esse motivo, encontra-se no ambiente hospitalar habitualmente frequentado a oportunidade de aproximação para realização de uma prática que transforma o contexto que gira em torno da patologia em um local de brincadeiras e formação de novos amigos. Ao se transformar o ambiente, provoca-se uma mudança em todos os elementos do microssistema, o que representa, segundo Bronfenbrenner (2002), "um exemplo especial de experimento, que, inevitavelmente, altera o comportamento dos participantes, podendo afetar o curso do desenvolvimento de maneira mais efetiva do que modificações em apenas um elemento porvez"(Bronfenbrenner, 2002, p. 32).

Acreditando que uma criança não pode realizar atividades recreativas e sustentar padrões de relacionamento interpessoal "sem sentir-se motivada ou sem adquirir uma concepção mais ampliada e diferenciada do meio ambiente" (Bronfenbrenner, 2002, p. 220), sustenta-se, com Bronfenbrenner (2002), que quando estas atividades acontecem algum desenvolvimento já ocorreu. Acreditando que uma criança não pode realizar atividades recreativas e sustentar padrões de relacionamento interpessoal sem se sentir motivada ou sem adquirir uma concepção mais ampliada e diferenciada do meio ambiente, sustenta-se, com Bronfenbrenner (2002), que quando estas atividades acontecem algum desenvolvimento já ocorreu.

Chega-se, assim, ao objetivo deste estudo, que foi verificar a influência potencial de atividades lúdicas, realizadas no contexto hospitalar, sobre os processos desenvolvimentais de crianças com PC, a partir da análise dos elementos do microssistema de Urie Bronfenbrenner.

\section{Método}

Partindo de uma abordagem qualitativa, esta pesquisa se caracterizou como um estudo de caso interpretativo, no qual o pesquisador busca uma compreensão em profundidade de uma única situação ou fenômeno (Thomas \& Nelson, 2002).

As descrições e interpretações são utilizadas para apoiar afirmações teóricas, procurando entendê-las de forma contextualizada (Triviños \& Molina, 2004).

O"ambiente de atividades" pode ser considerado a sala de espera da Fisioterapia Neurológica Infantil do HC/UNICAMP. Trata-se de um local de aproximadamente $44 \mathrm{~m}^{2}$, no próprio corredor do hospital, onde mães e crianças aguardam pelo atendimento fisioterápico. Onde anteriormente havia somente alguns bancos, encontra-se hoje um ambiente acolhedor, adequadamente decorado com pinturas de motivos infantis e brinquedos variados.

\section{Participantes}

Participaram deste estudo quatro díades mãe/criança com PC que frequentam a Fisioterapia Neurológica Infantil.

Os critérios para seleção das díades foram: assiduidade ao atendimento fisioterápico (participação em ao menos 20 dos 30 encontros realizados), concordância das mães em participar de todas as etapas da pesquisa e diagnóstico médico de PC (com comprometimento motor severo). O sexo da criança e a idade não foram considerados na escolha dos participantes.

\section{Procedimentos}

Brincadeiras tradicionais - lembradas pelas mães ou propostas pela pesquisadora - prevaleceram durante os encontros, entre elas:"amarelinha","esconde-esconde", pintura, "casinha", "bolinha de sabão", brincadeiras com arco, brincadeiras com bexiga," volençol", bola ao cesto, skate, entre outras.

As adaptações, ou "pequenos ajustes", surgiam espontaneamente, muitas vezes com a própria sugestão das mães; por exemplo, sentar no skate com a mãe, estourar bolinhas de sabão com as mãos (as crianças 
não conseguem soprar), utilizar um grande arco como cesto e bexigas (mais leves e mais lentas) ao invés de bolas e, naturalmente, as mães, de forma amorosa,"conduziam" os movimentos de seus filhos sempre que necessário, sem confundir tal atitude com exercícios terapêuticos.

A frequência dos encontros foi de uma vez por semana, ao longo de dez meses. A pesquisadora permanecia no "ambiente de atividades" por um período de três horas. As crianças recebiam 45 minutos de atendimento fisioterápico e participavam das atividades propostas por aproximadamente uma hora antes e uma hora após a terapia.

\section{Instrumentos}

Para atender aos objetivos propostos neste estudo, os instrumentos de pesquisa foram: entrevista semiestruturada com as mães e observação participante (as observações foram registradas em um "diário de campo").

A detecção da influência ambiental nos processos desenvolvimentais só é possível quando se emprega um modelo teórico consistente que permita tal observação. Neste estudo, trilhou-se o caminho da "Ecologia do Desenvolvimento Humano" de Bronfenbrenner (2002). As concepções ecológicas do autor sobre desenvolvimento-no-contexto e elementos do microssistema nortearam as observações.

Os fatores atividade, papel e relação interpessoal, como elementos, ou "blocos construtores", do microssistema, definiram o campo de observação.

\section{Resultados e Discussão}

Partindo do registro realizado durante o processo de observação participante (diário de campo) e dos relatos obtidos por meio de entrevista semiestruturada com as mães, apresentam-se os resultados de forma descritiva e interpretativa, unindo a prática na Fisioterapia Neurológica Infantil do HC/UNICAMP à "Ecologia do Desenvolvimento Humano de Bronfenbrenner" (2002).
A definição de atividade molar (primeiro elemento do microssistema) enfatiza a presença da intenção, ou desejo de se fazer o que se está fazendo. No entanto, Lewin (1975) salienta que experiências de êxito têm um efeito marcante sobre o "encorajamento", especialmente quando há uma combinação de êxito e elogio. A seguinte anotação do diário de campo confirma tal afirmativa:

C4 $4^{3}$ costuma se dispersar facilmente sempre que
encontra dificuldades. No entanto, hoje, durante nossa
brincadeira de" amarelinha", percebio quanto seesforçava
para pular em um pé só e, em seguida, com os dois pés
(para ele pular com os dois pés é mais difícil). Todos
comemoraram sua conquista, o que o deixou entu-
siasmado.

Segundo Bronfenbrenner (2002), a realização de atividades molares demonstra a habilidade da criança de influenciar o meio ambiente de acordo com seus desejos e necessidades. A criança se torna, assim, capaz de fazer suas próprias escolhas.

Quando chega no "Espaço Jardim Oficina", C1 fica agitada querendo brincar. Com o passar do tempo começamos a compreender seus olhares e sorrisos (ela não fala) e, assim, ela consegue escolher as brincadeiras. Fica especialmente feliz quando brincamos na casinha, de esconde-esconde e com o skate. Hoje perguntamos se queria brincar de "esconde-esconde" e ela sorriu de modo afirmativo.

\section{Relações interpessoais e papéis}

“Embora as atividades molares possam ser realizadas solitariamente, o envolvimento de outras pessoas constitui a mais importante fonte de efeitos diretos do meio ambiente sobre o desenvolvimento" (Bronfenbrenner, 2002).

Infelizmente, o mundo da criança com PC tende a ser socialmente empobrecido. Tal isolamento a impede de interagir com pessoas com as quais ela poderia desenvolver um apego sólido.

Eu gostaria que ele (C2) frequentasse uma escolinha, ficasse mais tempo num grupo, mas onde eu levo ele na terapia (na cidade onde mora), dizem que ele não vaiter

\footnotetext{
558 A identificação das crianças pela letra C seguida de um número tem o intuito de preservar suas identidades.
} 
melhora, quejáédeficiente... não adiantaria pôr ele numa escolinha. Lá tem escolinha pra criança com síndrome de Down, criança que aprende alguma coisa, faz alguma coisa. Então... no caso dele é assim, não faz nada, não precisa. Não adianta ele ficar lána escola porque ele não senta sozinho, não come sozinho. Esse convívio pra ele não significa nada. É uma coisa revoltante, porque eu acho que de repente, ele no meio das outras crianças, convivendo. Sabe, convivendo as crianças aprendem o que o outro faz. Eu acho que seria bom pra ele. Mas não acham que éo caso dele.

Com o objetivo de minimizar os efeitos de tal privação, buscou-se oportunizar atividades lúdicas que favorecessem uma variedade de relações, sem, no entanto, confundi-las com outros propósitos terapêuticos. Os dados obtidos foram descritos e analisados em termos de relações diádicas, partindo de sua primeira forma funcional - díade observacional.

Cl observava atentamente outra criança brincando na "casinha". Perguntei se queria brincar tambéme ela sorriu afirmativamente. Entramos na "casinha" e em pouco tempo as duas brincavam juntas. A outra menina fingia dar "comidinha" para C1 e ela, por sua vez, demonstrava gostar da brincadeira, sempre sorrindo. M1 costuma comentar que C1 não brinca com outras crianças eo "Espaço Jardim Oficina" tem dado essa oportunidade a ela.

Ao estruturar a atividade acima descrita de modo que as duas crianças operassem juntas, buscou-se proporcionar padrões de interação mais complexos, caracterizados pela reciprocidade.

Para Bronfenbrenner (2002), o desenvolvimento é facilitado quando as atividades observacionais ou conjuntas são realizadas com alguém com quem a criança desenvolveu um significativo e duradouro laço emocional.

São justamente estas relações afetivas positivas e recíprocas que caracterizam a terceira forma diádica - díade primária. Esta, por sua vez, encontra seu mais belo e expressivo exemplo na relação mãe-filho. No curso desse intercâmbio emocional, mãe e filho vivem, juntos, profundas experiências desenvolvimentais.

Em casa eu brinco com ele (C2), mas eu não tenho tempo prame divertir. Eu tento fazer ele se divertir prapoderfazer as coisas de casa. Eu fico preocupada com as minhas coisas, na verdade. Eaqui não... A gente se distrai junto. Tem as atividades, as coisas que a gente aprende, émuito bom.

Conclui-se, pelo relato acima, que a qualidade, e não apenas a quantidade, da interação materno-infantil deve ser sempre observada. E, nesse aspecto, a presença de terceiras pessoas exerce considerável influência no comportamento da díade, na medida em que essas terceiras pessoas apoiam as atividades da díade original e favorecem o estabelecimento de novas díades primárias.

No brincar aquino hospital, eu acabeipegando amizade com outras mães. Eu sempre vinha com a (outra mãe) naperua e não tinha intimidade. Agora, brincando com você (pesquisadora), a amizade ficou enorme. Ela mudou de cidade e faz uma falta danada. É muito bom saber que quando a gente falta na terapia alguém vai sentir sua falta também. A pessoa não vai dizer: 'Você tá perdendo consulta.' Ela vai falar assim: 'Você faltou, aconteceu alguma coisa? Vocêtá precisando de alguma coisa? Isso é muito bom.

As afirmações permitem concluir que a transformação ambiental afetou não somente o desenvolvimento das crianças, mas também o comportamento das mães. Nesse aspecto, as oportunidades oferecidas para o estabelecimento de novos vínculos e atividades conjuntas foram significativas para a formação de novos relacionamentos primários.

Stainback e Stainback (1999) lamentam que, embora a maioria de nós não consiga imaginar a própria vida sem o apoio, estímulo e companhia dos amigos, o desenvolvimento de tais relacionamentos por crianças com deficiência é frequentemente negligenciado. Embora as amizades não possam ser "forçadas", podem ser "encorajadas". A proximidade física, por exemplo, pode ser considerada um pré-requisito, conquanto não seja suficiente. Há muitos casos de crianças com PC "colocadas" em classes de educação regular, próximas de outras crianças, mas com atribuições individuais, como se pode observar no seguinte relato:

Na escola o (C3) não participa das aulas de Educação Física porque já fica mais complicado. Devido a ele ta usando o andador... não conseguirjogar bola... ele fica no pátio com a professora da sala, com uma outra brincadeira, mas não com todas as crianças. No recreio ele come a merenda com as crianças. Depois eles vão brincar. Aísepara... tem criançaquevaipra grama... tem aquelas 
que vão pro pátio... e ele fica sentadinho no chão brincando com pecinha... com brincadeira que dá certo praele.

O desenvolvimento de amizades - ou relacionamentos diádicos primários - requer oportunidades de interação no sentido estrito da palavra, ou seja, ação recíproca. À medida que os relacionamentos aumentam, as amizades se desenvolvem.

A gente vinha no hospital e quando terminava a fisioterapia a gente não ficava aqui porque não tinha o que fazer. Ficava láfora. Aíele não gostava de vir. Acabavase tornando cansativo pra ele. Com as brincadeiras do 'espaço jardim oficina' melhorou mais na afinidade das crianças. O (C4) mesmo, quando ele não vem, o (C3) acha falta. Mesmo com as outras crianças ele acha falta.

A crescente participação em atividades conjuntas, com outros adultos e crianças, facilitou e motivou o envolvimento das díades em padrões progressivamente mais complexos de relações interpessoais. As mães expressaram um comportamento significativamente mais afetuoso com seus filhos, falando e sorrindo mais para eles durante as atividades, e ambos, mães e crianças, demonstraram padrões de interação modificados (de forma positiva) pela presença e participação de outras pessoas. Tais alterações comportamentais permitiram o desenvolvimento de novos vínculos, ou seja, de novas amizades.

Lewin (1965) considera que o status recebido no grupo equivale a êxito ou fracasso. Ao serem aceitas pelo grupo de atividades, as crianças experimentaram o sentimento de êxito e, consequentemente, o sentimento de "fazer parte" que, no decorrer deste estudo, foi o principal propósito. As mães, por sua vez, ao encorajarem a participação de seus filhos, puderam vivenciar, igualmente, novas amizades e principalmente experimentar a alegria de perceberem seus filhos plenamente aceitos, sem restrições, sentimento que se pode seguramente chamar de amor.

Ele chega aqui cansado, emburrado. Aí você (pesquisadora) pega ele e vai fazer as brincadeiras. O contato com colos diferentes, isso vale, ele fica bem. Eu percebi agora que ele vai com as pessoas. Eu acho bom isso, porque é legal ter uma pessoa assim, que não tem medo de pegar ele, brincar com ele. E aqui ele tem isso (grifo nosso).

\section{Considerações Finais}

Ao partir do pressuposto de que "o desenvolvimento é um produto da interação do indivíduo com o meio", considera-se que as condições ambientais determinam cada aspecto do comportamento da criança, sendo os fatores sociais especialmente determinantes. A criação de espaços que respondam às necessidades da criança com PC torna-se, assim, fundamental para o pleno desenvolvimento. Porém,"montar cantinhos" não basta. É preciso uma proposta que ofereça oportunidades para a construção de novas formas de convívio, com atividades e pessoas com as quais a criança possa estabelecer relações de reciprocidade e, consequentemente, de mútua aceitação e amizade.

As mães se sentem fragilizadas ao verem seus filhos rejeitados e, instintivamente, querem protegê-los, limitando ainda mais seu espaço relacional. Por esse motivo, buscou-se o ambiente hospitalar, habitualmente frequentado, para realizar a prática, transformando o contexto que gira em torno da doença em um local de brincadeiras e formação de novos amigos.

Assim como o envolvimento familiar é a chave para a reabilitação, acredita-se que a participação das mães em atividades recreativas é fonte de motivação e encorajamento para seus filhos. No entanto, o aspecto mais surpreendente de tal participação, durante a realização deste estudo, foi a formação de laços de amizade entre as mães participantes, revelando suas necessidades de trocar experiências, de serem compreendidas e, principalmente, de conviverem com pessoas que não sentem hostilidade em relação a seus filhos. Em geral as pessoas sentem receio de segurá-los, abraçá-los e participar de atividades que teriam prazer de compartilhar com outras crianças.

Da mesma forma que as crianças, as mães também precisam de atenção que lhes transmita segurança e confiança e, assim como seus filhos, elas são igualmente únicas, apresentando respostas individuais em relação à deficiência. Encontrar pessoas de apoio, que tenham tempo para ouvi-las, não é fácil. Independentemente de sua reação diante da deficiência, a mãe sentirá necessidade de orientação e informação profissional. Mas estas não devem se limitar ao conhecimento da patologia e dos cuidados especiais. É preciso 
que a mãe compreenda, com o auxílio de um profissional devidamente preparado, a necessidade que seu filho tem de explorar o mundo. A criança sem deficiência geralmente encontra formas de satisfazer tal necessidade em contato com o ambiente físico e social.

Considerando a interação diádica, principal objeto deste trabalho, observou-se que também as mães experimentaram um crescimento psicológico durante o período de estudo, demonstrando um comportamento significativamente mais afetuoso com seus filhos e formando novos e significativos laços de amizade.

Um dos maiores problemas enfrentados pelas mães de crianças com PC é enfrentar o isolamento social causado pelo comprometimento físico de seu filho, privando ambos de interações de prazer e amizade.

Confirmando, por meio da prática, as hipóteses delineadas por Urie Bronfenbrenner em sua "Ecologia do Desenvolvimento Humano", conclui-se que questões ambientais devem ir além de considerações teóricas. $\mathrm{O}$ intuito é transpor tais conhecimentos para todo e qualquer ambiente frequentado por crianças com PC.

Em geral, a ideia prevalente ao se reportar a crianças com PC é a inadequação do desenvolvimento como fruto da lesão. A preocupação maior está no diagnóstico e nos procedimentos "corretivos". No entanto, é preciso que o foco de atuação não se restrinja à deficiência em si, mas é necessária uma reestruturação da ordem social existente, permitindo uma ecologia mais humana, criando-se novos microssistemas que atendam às necessidades da criança.

É importante salientar que, no Brasil, encontraram-se mais atuações referentes à recreação hospitalar que são dignas de nota, mas, de modo geral, o universo hospitalar gira em torno da doença, e a constante falta de recursos para o setor da saúde não permite que os profissionais valorizem e estimulem tais iniciativas. Quando existem, são, em geral, ligadas ao voluntariado, que muitas vezes utiliza recursos próprios na compra ou arrecadação de brinquedos, sem a devida valorização. Aqui se abre um campo de pesquisa e atuação que, ao demonstrar e valorizar a importância das atividades lúdicas para o desenvolvimento infantil como um todo, poderá oferecer oportunidades para que crianças com PC desenvolvam habilidades de adaptação social por meio de interações cooperativas que Ihes ofereçam apoio e autoconfiança.

\section{Referências}

Ajuriaguerra, J. (1980). Manual de psiquiatria infantil (2a. ed.). Rio de Janeiro: Atheneu.

Bronfenbrenner, U. (2002). A ecologia do desenvolvimento humano: experimentos naturais e planejados. Porto Alegre: Artes Médicas.

Bronfenbrenner, U. (2005). Making human beings human: bioecological perspectives on human development. California: Sage Publications.

Buscaglia, L. (1993). Os deficientes e seus pais (2a. ed.). Rio de Janeiro: Record.

Levitt, S. (2001). Otratamento da paralisia cerebrale do retardo motor (3a.ed.). São Paulo: Manole.

Lewin, K. (1965). Teoria de campo em ciência social. São Paulo: Livraria Pioneira Editora.

Lewin, K. (1975). Teoria dinâmica da personalidade. São Paulo: Cultrix.

Maturana, H., \& Verden-Zöller, G. (2004). Amar e brincar: fundamentos esquecidos do humano. São Paulo: Palas Athena.

Stainback, S., \& Stainback, W. (1999). Inclusão: um guia para educadores. Porto Alegre: Artmed.

Thomas, J., \& Nelson, J. (2002). Métodos de pesquisa em atividade física (pp.294-295). Porto Alegre: Artmed.

Trivinõs, A., \& Molina, V. (2004). A pesquisa qualitativa na educação física: alternativas metodológicas (2a. ed.). Porto Alegre: UFRGS.

Recebido em: 5/11/2007

Versão final reapresentada em: 28/5/2008

Aprovado em: 25/6/2008 